\title{
A Unified Framework For Water Erosion And Deposition Equations
}

\author{
B. $\mathrm{Yu}$
}

\begin{abstract}
Two modeling frameworks have been developed to describe and predict soil erosion and sediment deposition in recent years. The first is based on the concept of transport capacity. Deposition occurs only when the transport capacity is exceeded. This approach has been implemented in WEPP (Water Erosion Prediction Project) and several other physically based erosion prediction models. An alternative approach is based on simultaneous erosion and deposition. Net erosion or deposition is seen as a result of the dynamic interactions among all processes involved. The simultaneous erosion and deposition approach lays the foundation for GUEST (Griffith University Erosion System Template) and for recent studies of multi-size sediment deposition. This paper uses the original governing equations for WEPP and GUEST to represent the two approaches to water erosion and deposition modeling. The paper shows analytically that the two sets of governing equations, while vastly different in their appearance, share an identical structure, and thus can be reduced to a common set of equations unifying both approaches. The unified framework involves four terms: (i) sediment concentration at the transport limit, (ii) flow detachment, (iii) sedimentation because of gravity, (iv) a rainfall-driven sediment source term. The two modeling frameworks show only minor differences in how these four terms are formulated. Analytical solutions to the unified erosion and deposition equations show that the characteristic length for erosion is the ratio of maximum sediment discharge to maximum rate of detachment, and the characteristic length for deposition is the ratio of minimum sediment discharge to minimum rate of deposition, or simply the ratio of unit discharge to fall velocity. The paper clarifies and simplifies the current approaches to erosion and deposition modeling.
\end{abstract}

$\mathrm{T}$ WO ALTERNATIVE APPROACHES to water erosion and deposition modeling have been developed in recent decades to predict the rates of soil erosion and sediment deposition over the landscape. Characteristic of the first approach is the concept of sediment transport capacity (Foster and Meyer, 1972; Foster, 1982). Sediment deposition occurs only when this transport capacity is exceeded. The concept of transport capacity thus plays a pivotal role in erosion and deposition models. This approach to erosion and deposition modeling based on sediment transport capacity was adopted for WEPP (Nearing et al., 1989; Foster et al., 1995; Laflen et al., 1997). A very similar approach was used for other physically based erosion prediction models such as LISEM and EUROSEM (de Roo et al., 1996; Morgan et al., 1998).

Another approach to erosion and deposition modeling is based on the concept of simultaneous erosion and deposition (Rose et al., 1983; Rose, 1985; Hairsine and Rose, 1991; Hairsine and Rose, 1992). In this approach, three continuous processes of rainfall detachment, flow

B. Yu, Faculty of Environmental Sciences, Griffith University, Nathan, Qld 4111, Australia. Received 17 Oct. 2001. *Corresponding author (b.yu@mailbox.gu.edu.au).

Published in Soil Sci. Soc. Am. J. 67:251-257 (2003). detachment, and sediment deposition are considered simultaneously. This approach has received experimental support (Proffitt et al., 1991; Proffitt et al., 1993; Huang et al., 1999; Heilig et al., 2001), and lays the foundation for GUEST (Misra and Rose, 1996; Rose et al., 1997). More recently, this approach has been used to model multi-class sediment deposition (Beuselinck et al., 2002; Hairsine et al., 2002; Sander et al., 2002).

The two modeling frameworks for soil erosion prediction have been reviewed in parallel (Rose, 1993; Rose, 1998). No critical analysis of the erosion and deposition equations has been attempted to identify and clarify the similarity and differences between the two frameworks. The objective of this paper is to distill from the two seemingly disparate sets of equations a unifying set of equations governing soil erosion and sediment deposition. This paper attempts at clarifying the current situation with different modeling frameworks, and highlights the challenges in formulating mathematical descriptions of detachment, transport, and deposition processes.

\section{MATERIALS AND METHODS}

In this section, the two alternative sets of erosion and deposition equations are summarized in their original form. Equations implemented in the current version of WEPP were considered to represent the transport capacity approach (Foster et al., 1995), while the set of equations developed by Hairsine and Rose $(1991,1992)$ was used to represent the simultaneous erosion and deposition approach.

\section{WEPP}

The governing equation for sediment movement in a rill is

$$
\frac{\mathrm{d} G}{\mathrm{~d} x}=D_{f}+D_{i}
$$

where $G$ is sediment discharge per unit flow width $\left(\mathrm{kg} \mathrm{m}^{-1}\right.$ $\left.\mathrm{s}^{-1}\right) ; D_{f}$, the rill erosion or deposition rate $\left(\mathrm{kg} \mathrm{m}^{-2} \mathrm{~s}^{-1}\right) ; D_{i}$, interrill sediment delivery rate $\left(\mathrm{kg} \mathrm{m}^{-2} \mathrm{~s}^{-1}\right)$; and $x$, the distance in the downslope direction (m). Note that the governing Eq. [1] is based on mass balance of sediment in rills. Net erosion in rills is modeled in WEPP by

$$
D_{f}=K_{r}\left(\tau_{f}-\tau_{c}\right)\left(1-\frac{G}{T_{c}}\right)
$$

where $K_{r}$ is a rill erodibility parameter $\left(\mathrm{m}^{-1} \mathrm{~s}\right), \tau_{f}$ and $\tau_{c}$ are flow shear stress and critical shear stress $(\mathrm{Pa})$, respectively, and $T_{c}$ is sediment transport capacity $\left(\mathrm{kg} \mathrm{m}^{-1} \mathrm{~s}^{-1}\right)$. Equation [2] applies only when $G \leq T_{c}$. When net deposition occurs, that is, $G>T_{c}$, the $D_{f}$ term is given by:

$$
D_{f}=\frac{\beta V_{f}}{q}\left(T_{\mathrm{c}}-G\right)
$$

where $\beta$ is a raindrop induced turbulence coefficient, $V_{f}$ is the

Abbreviations: GUEST, Griffith University Erosion System Template; WEPP, Water Erosion Prediction Project. 
effective fall velocity of the sediment $\left(\mathrm{m} \mathrm{s}^{-1}\right)$ calculated from an effective particle diameter and specific gravity (Foster et al., 1995), and $q$ is unit discharge, that is, flow rate per unit flow width $\left(\mathrm{m}^{2} \mathrm{~s}^{-1}\right)$.

Interrill sediment delivery in WEPP is modeled by:

$$
D_{i}=K_{\text {iadj }} I_{e} \sigma_{i r} S D R_{R R} F_{\text {nozzle }}\left(\frac{R_{s}}{w}\right)
$$

where $K_{\text {iadj }}$ is adjusted interrill erodibility $\left(\mathrm{kg} \mathrm{m}^{-4} \mathrm{~s}\right), I_{e}$ is effective rainfall intensity $\left(\mathrm{m} \mathrm{s}^{-1}\right), \sigma_{i r}$ is the interrill runoff rate $\left(\mathrm{m} \mathrm{s}^{-1}\right), S D R_{R R}$ is a sediment delivery ratio, $F_{\text {nozzle }}$ is an adjustment factor to account for sprinkler irrigation impact energy variation, $R_{s}$ is the spacing of rills $(\mathrm{m})$, and $w$ is rill width $(\mathrm{m})$. Interrill erodibility is adjusted in WEPP to take into account the effects of canopy cover, ground cover, roots, and sealing and crusting (Alberts et al., 1995). The effective rainfall intensity is defined in WEPP as the average intensity evaluated for the period when rain rate exceeds infiltration rate (Foster et al., 1995). The interrill sediment delivery ratio is calculated in WEPP as a function of the random roughness of the soil surface, the fall velocity of individual particle-size classes of sediment, and the size distribution of the sediment (Foster et al., 1995; Flanagan and Nearing, 2000).

\section{GUEST}

The governing equation for sediment movement developed for GUEST can be written as:

$$
\frac{\partial\left(c_{\mathrm{i}} D\right)}{\partial t}+\frac{\partial\left(c_{\mathrm{i}} q\right)}{\partial x}=e_{i}+e_{d i}+r_{i}+r_{r i}-d_{i}
$$

where $D$ is water depth $(\mathrm{m}), c_{i}$ is the sediment concentration for particle-size class $i\left(\mathrm{~kg} \mathrm{~m}^{-3}\right), e_{i}$ and $e_{d i}$ are rates of rainfall detachment and redetachment $\left(\mathrm{kg} \mathrm{m}^{-2} \mathrm{~s}^{-1}\right), r_{i}$ and $r_{r i}$ are rates of flow entrainment and re-entrainment $\left(\mathrm{kg} \mathrm{m}^{-2} \mathrm{~s}^{-1}\right), d_{i}$ is the rate of deposition $\left(\mathrm{kg} \mathrm{m}^{-2} \mathrm{~s}^{-1}\right)$, and $t$ is the time (s). Note that the Eq. [5] is based on mass balance for individual particlesize classes. The five terms on the right-hand side of Eq. [5] were modeled as follows:

$$
\begin{gathered}
e_{i}=(1-H) \frac{a P^{\mathrm{p}}}{I} \\
e_{d i}=H a_{\mathrm{d}} P^{\mathrm{p}} \frac{M_{d i}}{M_{d t}} \\
r_{i}=(1-H) \frac{F\left(\Omega-\Omega_{\mathrm{o}}\right)}{I J} \\
r_{r i}=H \frac{\alpha_{i} F \sigma\left(\Omega-\Omega_{\mathrm{o}}\right)}{(\sigma-\rho) g D} \frac{M_{d i}}{M_{d t}} \\
d_{i}=\alpha_{i} v_{i} c_{i}
\end{gathered}
$$

where $H$ is the fraction of the original soil covered with deposited sediment, $a$ is a detachability parameter, $p$ is an exponent, $P$ is rainfall intensity $\left(\mathrm{m} \mathrm{s}^{-1}\right), I$ is an arbitrary number of size classes, $a_{d}$ is the detachability parameter for the deposited layer, $M_{d i}$ is the amount of sediment in size class $i$ in the deposited layer and $M_{d t}$ is the total amount of deposited sediment. Note the ratio $M_{d i} / M_{d t}$ represents the fraction of sediment in size class $i$ in the deposited layer. Other variables in Eq. [6] through [10] are defined as follows: $F$ is the fraction of stream power effective in entrainment and re-entrainment, $J$ is called specific energy of entrainment $\left(\mathrm{J} \mathrm{kg}^{-1}\right), \Omega$ and $\Omega_{\mathrm{o}}$ are stream power and threshold stream power per unit area $\left(\mathrm{W} \mathrm{m} \mathrm{m}^{-2}\right.$ ), respectively, $\sigma$ is the wet density of sediment and $\rho$ is the water density, both in kilogram per cubic meters $(\mathrm{kg}$ $\left.\mathrm{m}^{-3}\right), g$ is the gravitational acceleration $\left(\mathrm{m} \mathrm{s}^{-2}\right), \alpha_{i}$ is the ratio of the sediment concentration near the bed to the mean sediment concentration across the entire depth (Corley, 1982), and $v_{i}$ is the fall velocity for size class $i\left(\mathrm{~m} \mathrm{~s}^{-1}\right)$.

In Hairsine and Rose $(1991,1992), H$ was conceptualized as the fractional shielding of the original soil surface by the deposited layer. The sediment in suspension was seen to have originated from two sources. The first is the original soil, the second the deposited layer. $H$ has also been regarded as the fractional mass shielding of the soil from further erosion (Sander et al., 1996; Heilig et al., 2001). The notion of entrainment in GUEST is essentially the flow removal or detachment of the original soil (Rose, 1985). The parameter $J$ is a measure of soil erodibility, for $J$ represents the amount of energy required to entrain a unit mass of the original soil (Hairsine and Rose, 1992). Stream power in GUEST is defined as the energy expenditure per unit area and calculated as the product of shear stress and flow velocity.

In practice, both the exponent $p$ and the ratio $\alpha_{i}$ have been set to unity (Misra and Rose, 1996; Hairsine et al., 2002). Consequently, the units of measurement of $a$ and $a_{d}$ are kilogram per cubic meter $\left(\mathrm{kg} \mathrm{m}^{-3}\right)$. If we define $f_{o i}$ as the fraction of the original soil in size class $i$, then

$$
f_{o i}=\frac{1}{I}
$$

for size classes of equal mass. With these three modifications, that is, $p=\alpha_{i}=1$ and Eq. [11], the governing equation in GUEST can be rewritten as:

$$
\begin{aligned}
\frac{d\left(c_{i} q\right)}{\mathrm{d} x}= & {\left[(1-H) f_{o i} a+H a_{d} \frac{M_{d i}}{M_{d t}}\right] P+} \\
& {\left[\frac{(1-H) f_{o i}}{J}+\frac{H \sigma}{(\sigma-\rho) g D} \frac{M_{d i}}{M_{d t}}\right] F\left(\Omega-\Omega_{\mathrm{o}}\right)-v_{i} c_{i} }
\end{aligned}
$$

Note that Eq. [12] applies under steady state condition when neither $c_{i}$ nor $D$ changes in time; hence the first term in Eq. [5] vanishes.

\section{RESULTS}

In this section, we first recast the erosion and deposition equations used in WEPP to allow easy comparison. Equations in GUEST are rearranged for runoff-driven and rainfall-driven processes. A unified set of erosion and deposition equations are then derived to show that WEPP and GUEST are structurally identical under steady-state conditions. Finally the unified erosion and deposition equations are solved analytically and a numerical example given to illustrate the change in sediment concentration from an area of net erosion to an area of net deposition as a result of a sudden decrease in slope.

\section{WEPP Equations}

For WEPP, we use sediment concentration, $c$, and sediment concentration associated with the sediment transport capacity, $c_{t}$, and unit discharge, $q$, to replace $G$ with $q c$ and $T_{c}$ with $q c_{t}$ in Eq. [2]. In addition, we 
lump $K_{\text {iadj }} S D R_{R R} F_{\text {nozzle }}$ into a single interrill erodibility parameter $K_{i}\left(\mathrm{~kg} \mathrm{~m}^{-4} \mathrm{~s}\right)$. With these notational changes, we have, in case of net erosion:

$$
\frac{\mathrm{d}(c q)}{\mathrm{d} x}=K_{\mathrm{r}}\left(\tau_{\mathrm{f}}-\tau_{\mathrm{c}}\right)\left(1-\frac{c}{c_{\mathrm{t}}}\right)+K_{\mathrm{i}} \mathrm{I}_{\mathrm{e}} \sigma_{\mathrm{ir}} \frac{R_{\mathrm{s}}}{w}
$$

and for net deposition,

$$
\frac{\mathrm{d}(c q)}{\mathrm{d} x}=\beta V_{\mathrm{f}} c_{\mathrm{t}}\left(1-\frac{c}{c_{\mathrm{t}}}\right)+K_{\mathrm{i}} I_{\mathrm{e}} \sigma_{\mathrm{ir}} \frac{R_{\mathrm{s}}}{w}
$$

\section{GUEST Equations when Flow Dominates}

For the simultaneous erosion and deposition approach, we first ignore the terms associated with rainfall detachment and redetachment, and concentrate on the interaction between flow-driven erosion and deposition only. For flows in rills or preferred pathways, GUEST assumes that the flow-related entrainment and re-entrainment are the dominant erosion processes.

For steady state, the governing equation for sediment movement for size class $i$ when flow-driven processes dominates can be simplified as:

$$
\frac{\mathrm{d}\left(c_{i} q\right)}{\mathrm{d} x}=r_{i}+r_{r i}-d_{i}
$$

In the case of net erosion, the steady-state condition requires that the rate of deposition equals the rate of re-entrainment. If the rate of deposition, for instance, were greater than the rate of re-entrainment, there would be a net accumulation of deposited sediment over time, which is contrary to the assumption of a steady state. Thus, the deposited layer must remain invariant in time, and this can only be achieved if the re-entrainment term balances out the deposition term, that is

$$
r_{\mathrm{ri}}=d_{i}
$$

or from Eq. [9] and [10]:

$$
H \frac{F \sigma\left(\Omega-\Omega_{\mathrm{o}}\right)}{(\sigma-\rho) g D} \frac{M_{d i}}{M_{d t}}=v_{i} c_{i}
$$

Summing the equation above for all size classes, we have

$$
H=\frac{(\sigma-\rho) g D \sum v_{i} c_{i}}{\sigma F\left(\Omega-\Omega_{\mathrm{o}}\right)}
$$

We note that $c_{i}$ can be written as $c f_{i}$ where $f_{i}$ is the fraction of sediment in suspension in size class $i$. Consequently,

$$
\sum v_{i} c_{i}=c \Sigma f_{i} v_{i}
$$

We further define $v_{a}$ as the average fall velocity weighted by the fraction of suspended sediment in each size class, that is

$$
v_{a}=\sum_{i=1}^{n} f_{i} v_{i}
$$

where $n$ is the total number of particle-size classes. With Eq. [19] and [20], Eq. [18] can be rewritten as

$$
H=\frac{c}{c_{t}}
$$

with $c_{t}$ given by

$$
c_{\mathrm{t}}=\frac{\sigma F\left(\Omega-\Omega_{\mathrm{o}}\right)}{(\sigma-\rho) g D v_{\mathrm{a}}}
$$

Equation [21] represents a new interpretation of $H$ as a measure of the departure of actual concentration from that at the transport limit. Note also that Eq. [22] is identical to the expression for the equilibrium sediment concentration at the transport limit derived by Hairsine and Rose (1992). This expression for $c_{t}$ and its various subsequent modifications have been used in field applications (Ciesiolka et al., 1995; Rose et al., 1997; Yu and Rose, 1999; Yu et al., 1999). Inserting Eq. [21] into Eq. [8] and then Eq. [8] into Eq. [15], noting also Eq. [16], and taking summation over all size classes, we have

$$
\frac{\mathrm{d}(c q)}{\mathrm{d} x}=\frac{F}{J}\left(\Omega-\Omega_{\mathrm{o}}\right)\left(1-\frac{c}{c_{t}}\right)
$$

When net deposition occurs, the rills or flow pathways would be completely covered with deposited sediment. In the context of GUEST, the entrainment term vanishes and $H$ equals 1 , that is, $r_{i}=0$ from Eq. [8]. Note that from Eq. [9] the re-entrainment term, can be written as

$$
r_{r i}=H c_{t} v_{a} \frac{M_{d i}}{M_{d t}}
$$

With Eq. [24] to replace the re-entrainment term in Eq. [15] and taking summation over all size classes, we have

$$
\frac{\mathrm{d}(c q)}{\mathrm{d} x}=c_{t} v_{a}-\Sigma v_{i} c_{i}
$$

because $H=1$. Applying the definition of weighted fall velocity, that is, Eq. [20], we have the following:

$$
\frac{\mathrm{d}(c q)}{\mathrm{d} x}=v_{a} c_{t}\left(1-\frac{c}{c_{t}}\right)
$$

\section{GUEST Equations When Rain Dominates}

In areas where rainfall dominates the erosion processes, the governing equation in GUEST for size class $i$ is given by:

$$
c_{i} \frac{\mathrm{d} q}{\mathrm{~d} x}+q \frac{\mathrm{d} c_{\mathrm{i}}}{\mathrm{d} x}=e_{i}+e_{d i}-d_{i}
$$

The same argument leading to Eq. [16] also applies to the case when rainfall dominates the erosion processes. For steady state, the redetachment and deposition terms are thus balanced out, resulting in:

$$
e_{d i}=v_{i} c_{i}
$$

Using Eq. [7] for $e_{d i}$ with $p=1$ and summing over all size classes and using Eq. [28], [19], and [20] leads to an expression for equilibrium sediment concentration as

$$
v_{a} c=H a_{d} P
$$

The second term on the left-hand side of Eq. [27] was 
assumed to be negligible (Proffitt et al., 1991; Misra and Rose, 1996; Sander et al., 1996), implying that the sediment concentration does not vary in space in rainfall-dominated areas. It is also noted that

$$
\frac{\mathrm{d} q}{\mathrm{~d} x}=Q
$$

Thus the rainfall detachment for all size classes becomes the product of sediment concentration and runoff rate from Eq. [25]:

$$
c Q=e
$$

It follows from Eq. [31] and [29] that

$$
e=\frac{H a_{d}}{v_{a}} P Q
$$

\section{Unification of WEPP and GUEST equations}

Now we can rewrite the governing equation for GUEST with the following proviso

- mass balance is taken for the rills or flow pathways per unit flow width,

- flow dominates erosion and deposition processes in these rills or flow pathways,

- lateral sediment input is from areas where rainfall dominates the erosion processes,

- the source area for lateral sediment input per flow length is given by the spacing between rills or flow pathways, $R_{s}$,

- the lateral source area is an area of net erosion.

For net erosion, we have from Eq. [23] and [32],

$$
\frac{\mathrm{d}(c q)}{\mathrm{d} x}=\frac{F}{J}\left(\Omega-\Omega_{\mathrm{o}}\right)\left(1-\frac{c}{c_{\mathrm{t}}}\right)+\frac{H a_{d}}{v_{a}} P Q \frac{R_{s}}{w}
$$

and for net deposition, from Eq. [26] and [32],

$$
\frac{\mathrm{d}(c q)}{\mathrm{d} x}=v_{a} c_{t}\left(1-\frac{c}{c_{t}}\right)+\frac{H a_{\mathrm{d}}}{v_{a}} P Q \frac{R_{s}}{w}
$$

The ratio of $R_{s} / w$ in Eq. [33] and [34] converts the rate of detachment in the lateral source area into the rate of lateral sediment delivery per flow width. By comparing Eq. [33] to [13] and Eq. [34] to [14], it is clear that the governing equations for WEPP and GUEST are structurally identical. Despite conceptual differences, the two approaches are shown here to lead to equations that differ only in the ways in which individual terms are formulated.

The unifying equations for water erosion and deposition can be written in the following general form; for net erosion when $c \leq c_{t}$

$$
\frac{\mathrm{d}(c q)}{\mathrm{d} x}=\Phi\left(1-\frac{c}{c_{\mathrm{t}}}\right)+\Theta
$$

otherwise for net deposition when $c>c_{t}$

$$
\frac{\mathrm{d}(c q)}{\mathrm{d} x}=\Psi\left(1-\frac{c}{c_{\mathrm{t}}}\right)+\Theta
$$

The $\Phi$ term represents the upward movement of sediment from the original soil matrix, and the $\Psi$ term represents the downward movement of suspended sediment because of settling under gravity. More precisely, $\Phi$ is the maximum rate of detachment when the water is clear $(c=0)$, while $\Psi$ is the minimum rate of deposition because the actual rate of deposition $\left(v_{a} c\right)$ is always greater than $\Psi\left(=v_{a} c_{t}\right)$ in areas of net deposition. The $\Theta$ term is the source term representing the lateral sediment input. Interpretation of these terms in the context of WEPP and GUEST is summarized in Table 1.

\section{Solutions To Unified Equations And A Numerical Example}

Analytical solutions to Eq. [35] and [36] are sought to illustrate the unified framework for water erosion and deposition. When combined with sensible parameter values, these solutions give insight into how the sediment concentration varies when erosion or deposition occurs. To obtain analytical solutions, it is necessary to consider simple cases only. It is assumed that $q, \Phi, \Psi$, $\Theta$, and $c_{t}$, do not vary as a function of the distance, $x$, with the initial condition of $c=c_{0}$ at $x=x_{0}$. We further assume that sediment is of uniform size possessing a constant settling velocity of $v$. Without this assumption of uniform sediment, $c_{t}$ would vary as a function of $x$ when deposition occurs in the context of GUEST, because $c_{t}$ would increase as $v_{a}$ decreases with deposition of coarse sediment (equation, 22). For both GUEST and WEPP with $\beta=1$, the deposition term, $\Psi$, in Eq.

\begin{tabular}{|c|c|c|}
\hline Alternative approaches & Transport Capacity & Simultaneous erosion and deposition \\
\hline Representative modeling framework & WEPP & GUEST \\
\hline \multirow[t]{3}{*}{ Equivalent conceptions } & Interrill erosion & Rainfall-dominated processes \\
\hline & Interrill sediment delivery & Lateral sediment input \\
\hline & Rill erosion and deposition & Runoff-dominated processes \\
\hline \multirow{2}{*}{ Concentration at transport limit, $c_{t}$} & $T_{c} / q$ with $T_{c}$ a function of flow and soil characteristics & 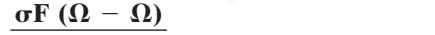 \\
\hline & 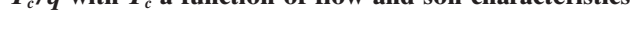 & $(\sigma-p) g D v_{a}$ \\
\hline Flow detachment, $\Phi$ & Proportional to excess shear stress & Proportional to excess stream power \\
\hline Parameters for flow detachment & & $F J^{-1}$ \\
\hline Sedimentation, $\Psi$ & Proportional to $c_{t}$ & Proportional to $c_{t}$ \\
\hline Parameters for sedimentation & $\boldsymbol{\beta} \boldsymbol{V}_{f}$ & $v_{a}$ \\
\hline Rain detachment (source term), $\Theta$ & Proportional to rainfall intensity & Proportional to rainfall intensity \\
\hline Parameters for rain detachment & $K_{\mathrm{i}}$ & $\mathbf{H a}_{\mathrm{d}} \mathbf{v}_{\mathbf{a}}^{-1}$ \\
\hline
\end{tabular}
[36] is given by:

$$
\Psi=v c_{\mathrm{t}}
$$

for uniform sediment. In WEPP, $\beta=1$ is used in the absence of raindrop impacts such as furrow irrigation

Table 1. A comparison of two alternative approaches to water erosion and deposition modeling. 
(Foster et al., 1995). The solution to Eq. [35] for erosion is

$$
\begin{aligned}
c= & c_{0} \exp \left[-\left(x-x_{\mathrm{o}}\right) / \lambda_{\mathrm{e}}\right]+c_{\mathrm{t}}\left(1+\frac{\Theta}{\Phi}\right) \\
& \left\{1-\exp \left[-\left(x-x_{\mathrm{o}}\right) / \lambda_{\mathrm{e}}\right]\right\}
\end{aligned}
$$

where $\lambda_{e}(\mathrm{~m})$ is a characteristic length for erosion given by:

$$
\lambda_{\mathrm{e}}=\frac{c_{\mathrm{t}} q}{\Phi}
$$

The numerator in Eq. [39] is the sediment transport capacity, $T_{c}$, in the context of WEPP. The characteristic length can therefore be interpreted as a ratio of maximum rate of sediment discharge to maximum rate of detachment. For the deposition Eq. [36], a similar solution can be easily derived:

$$
\begin{aligned}
c= & c_{\mathrm{o}} \exp \left[-\left(x-x_{\mathrm{o}}\right) / \lambda_{\mathrm{d}}\right]+ \\
& c_{\mathrm{t}}\left(1+\frac{\Theta}{\Psi}\right)\left\{1-\exp \left[-\left(x-x_{\mathrm{o}}\right) / \lambda_{\mathrm{d}}\right]\right\}
\end{aligned}
$$

where $\lambda_{d}(\mathrm{~m})$ is a characteristic length for deposition given by:

$$
\lambda_{\mathrm{d}}=\frac{q}{v}
$$

The physical meaning of this characteristic length for deposition is that $\lambda_{d}$ is the total distance a particle travels downslope when the particle settles a vertical distance equal to the water depth. The solutions above describe how the sediment concentration, and hence the sediment discharge, would vary down a uniform slope with uniform flow rate and soil properties. Let us consider a numerical example for the case of net erosion followed by net deposition. Clear water is fed at the top of the slope consisting of two segments with different slopes (Fig. 1). The initial condition therefore is that $c=0$ at $x=0$. The following parameter values were used:

$$
\begin{aligned}
c_{t l} & =100 \mathrm{~kg} \mathrm{~m}^{-3} \text { for the first segment with a } 10 \% \text { slope } \\
c_{t 2} & =10 \mathrm{~kg} \mathrm{~m}^{-3} \text { for the second segment with a } 1 \% \text { slope } \\
q & =0.001 \mathrm{~m}^{2} \mathrm{~s}^{-1} \\
\Phi & =0.1 \mathrm{~kg} \mathrm{~m}^{-2} \mathrm{~s}^{-1} \\
\Psi & =0.01 \mathrm{~kg} \mathrm{~m}^{-2} \mathrm{~s}^{-1} \\
\Theta & =0 \\
v & =0.001 \mathrm{~m} \mathrm{~s}^{-1}
\end{aligned}
$$

The magnitude of the unit discharge represents the steady-state unit discharge at the end of a hill slope with a slope length of $10 \mathrm{~m}$, runoff rate of $36 \mathrm{~mm} \mathrm{~h}^{-1}$ and a $R_{s} / w$ value of 10 . With respect to WEPP, a $\Phi$ value of $0.1 \mathrm{~kg} \mathrm{~m}^{-2} \mathrm{~s}^{-1}$ may be related to a situation where the rill erodibility $K_{r}=0.01 \mathrm{~m}^{-1} \mathrm{~s}$ and $\left(\tau_{f}-\tau_{c}\right)=10 \mathrm{~Pa}$. Note that the suggested limits for the baseline $K_{r}$ values are from 0.002 to $0.05 \mathrm{~m}^{-1} \mathrm{~s}$ (Alberts et al., 1995). For GUEST, the same $\Phi$ value is obtained when $F=0.1$,

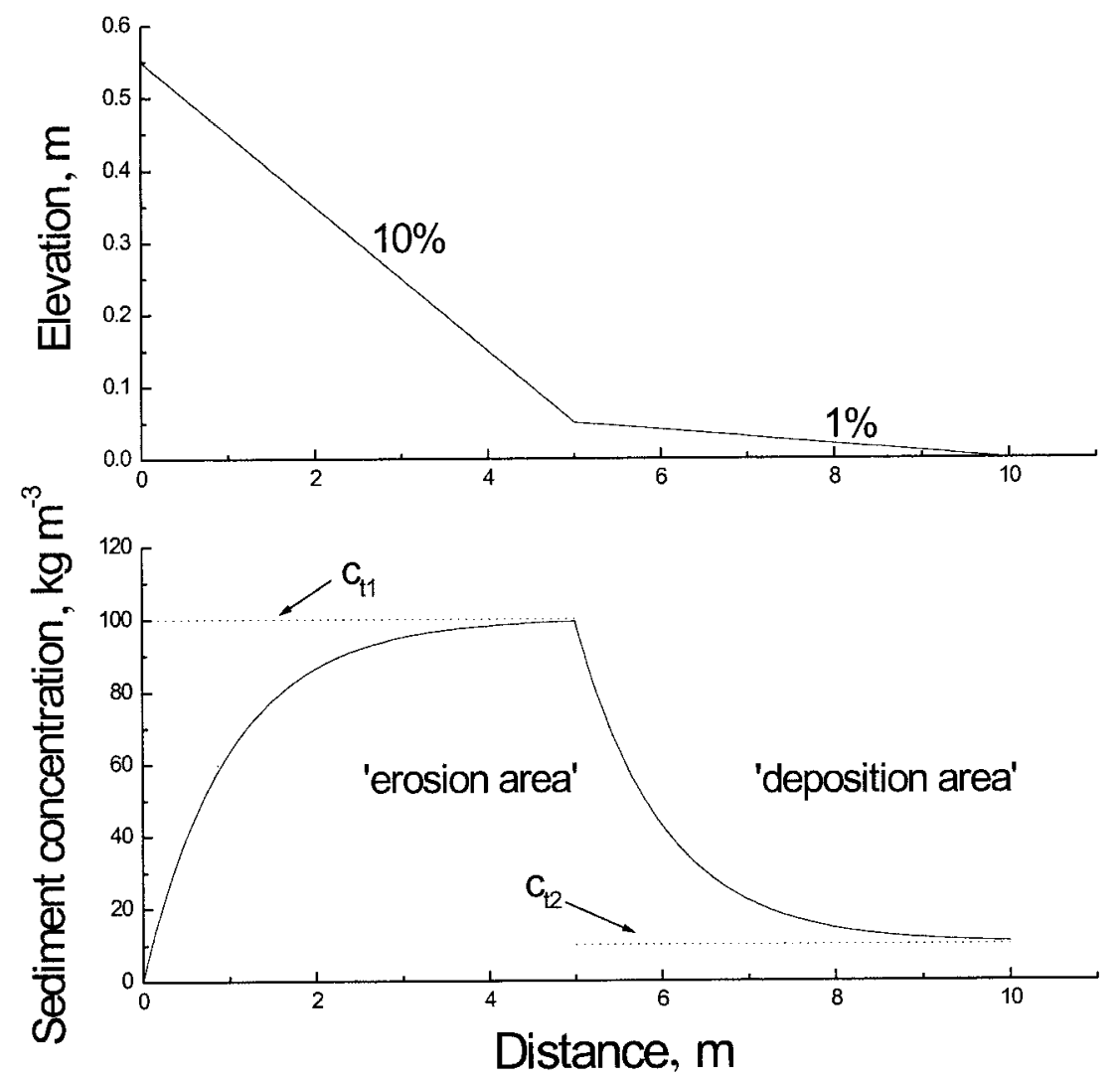

Fig. 1. Solutions to the unified erosion and deposition equations to show the downslope variation in sediment concentration as a result of a sudden decrease in slope steepness. See the text for parameter values used for this illustration. 
$J=10 \mathrm{~J} \mathrm{~kg}^{-1}$ and $\left(\Omega-\Omega_{\mathrm{o}}\right)=1 \mathrm{~W} \mathrm{~m}^{-2}$. While there is no extensive database for $F$ and $J$ values, Misra and Rose (1995) reported an average $J$ value of $8.5 \mathrm{~J} \mathrm{~kg}^{-1}$ with $F$ varying from 0.18 to 0.25 for a Krasnozem $(34 \%$ clay, $26 \%$ silt). The fall velocity of $0.001 \mathrm{~m} \mathrm{~s}^{-1}$ is related to particle size of $0.0394 \mathrm{~mm}$ (in the range for fine sand), assuming sediment density of $2600 \mathrm{~kg} \mathrm{~m}^{-3}$ and kinematic viscosity of $10^{-6} \mathrm{~m}^{2} \mathrm{~s}^{-1}$ (Cheng, 1997).

For this numerical example, the characteristic length for erosion and deposition is the same and equals $1 \mathrm{~m}$ from Eq. [39] and [41]. Fig. 1 shows the variation of the sediment concentration as a function of the distance down slope using this set of parameter values. Concentration increases when net erosion occurs; and concentration decreases during net deposition. For this example, the sediment concentration is increased from 0 at $x=0$ to $99.3 \mathrm{~kg} \mathrm{~m}^{-3}$ at $x=5 \mathrm{~m}$, and then decreased to $10.6 \mathrm{~kg} \mathrm{~m}^{-3}$ at $x=10 \mathrm{~m}$ (Fig. 1).

A decrease in slope does not necessarily imply immediate deposition. If the soil is less erodible, that is $K_{\mathrm{r}}<$ $0.01 \mathrm{~m}^{-1} \mathrm{~s}, \Phi$ would decrease while characteristic erosion length would increase. It is possible that the sediment concentration is still less than the transport capacity for the second segment with a lower slope. In fact, when $\Phi=0.0021 \mathrm{~kg} \mathrm{~m}^{-2} \mathrm{~s}^{-1}$ for this example, $\lambda_{e}=47.6 \mathrm{~m}$, and $c=10 \mathrm{~kg} \mathrm{~m}^{-3}$ at $x=5 \mathrm{~m}$ from Eq. [38] and [39]. Thus, when $\Phi<0.0021 \mathrm{~kg} \mathrm{~m}^{-2} \mathrm{~s}^{-1}$ no deposition would occur on either segments. At the other extreme, the entire slope can become an area of net deposition when the initial concentration at the top of the slope exceeds $100 \mathrm{~kg} \mathrm{~m}^{-3}$, the assumed sediment concentration at the transport limit for the upper segment.

\section{DISCUSSION}

A number of points require further clarification. First, this comparative analysis of the governing equations for WEPP and GUEST is based on the steady-state assumption. Cancellation of the settling and re-entrainment and redetachment terms will only hold under steady-state conditions. Investigations of unsteady sediment movement have been attempted using the simultaneous erosion and deposition approach (Sander et al., 1996; Hairsine et al., 1999; Heilig et al., 2001), but this is beyond the scope of this paper. Second, the critical step in unifying these two seemingly disparate modeling frameworks is an alternative interpretation of $H$, that is, Eq. [21]. This paper shows that $H$, under steadystate conditions, can be regarded as the ratio of actual sediment concentration over that at the transport limit. For areas of net erosion, the ratio is less than unity; for areas of net deposition, the ratio is greater than unity. $H$ becomes a measure of the departure from sediment concentration at the transport limit. In this paper, interpretation of $H$ has been generalized to include both erosion and deposition. In previous interpretations of Hairsine and Rose (1991), Sander et al. (1996), and Heilig et al. (2001), $H$ is automatically set to 1 in net deposition solutions, and thus has limited meaning in practical terms when net deposition occurs. Third, the weighted average settling velocity, $v_{a}$, is best interpreted as a dynamic variable, which varies as the composition of the suspended sediment varies, for instance, particularly over areas of net deposition. Hence, $c_{t}$, being dependent on $v_{a}$, also varies dynamically in areas of net deposition as a function of the composition of the suspended sediment.

This paper clearly shows that erosion and deposition equations used in WEPP can be derived from the simultaneous erosion and deposition approach with minor modifications as pointed out before. This paper also shows that under steady-state conditions, detachment and redetachment are mutually exclusive, and so are entrainment and re-entrainment. Some of the terms in the context of GUEST always vanish depending on whether it is net erosion or deposition. In addition, it can be argued that the approach to erosion and deposition modeling and the associated governing equations are not as important as how individual processes are formulated because both approaches are structurally the same. Most of the current process-based erosion models differ only in the way in which each of the four terms is formulated. Within this unified framework for steady state erosion and deposition equations, the challenges lie ahead in how best to formulate the relationships describing detachment, transport, and deposition, and how to estimate the parameter values for these relationships to enable prediction of soil erosion and sediment deposition reliably and at minimum cost.

\section{CONCLUSION}

With an aim to distill from the two alternative approaches to mathematical descriptions of the erosion and deposition processes a unifying framework for erosion and deposition equations developed in this paper shows that under steady-state conditions, the governing equations in WEPP and GUEST are structurally identical. They differ only in the way in which rainfall and flow detachments and sedimentation terms are formulated, and both require the sediment concentration at the transport limit that depends on the characteristics of the flow, the soil, and the suspended sediment. The paper reinterprets the shielding factor $H$ in the context of GUEST simply as the ratio of actual sediment concentration to that at the transport limit. Analytical solutions to the unified erosion and deposition equations show that the characteristic length for erosion is the ratio of maximum sediment discharge to maximum rate of detachment, and the characteristic length for deposition is the ratio of minimum sediment discharge to minimum rate of deposition, or simply the ratio of unit discharge to fall velocity.

\section{ACKNOWLEDGMENTS}

This work was made possible through a project on sediment and pollutant delivery from upland catchment supported by Collaborative Research Centre for Catachment Hydrology, Australia. The author is grateful to anonymous reviewers for SSSAJ for their most constructive comments. The author also thanks George Foster, Peter Kinnell, Mark Nearing, and Cal- 
vin Rose for their most encouraging comments on an early draft of this paper.

\section{REFERENCES}

Alberts, E.E., M.A. Nearing, M.A. Weltz, L.M. Risse, F.B. Pierson, X.C. Zhang, J.M. Laflen, and J.R. Simanton. 1995. Ch. 7 Soil component. p. 7.1-7.45. In D.C. Flanagan and M.A. Nearing (ed.) USDA-Water Erosion Prediction Project: Hillslope Profile and Watershed Model Documentation. NSERL Rep. No. 10. USDAARS Nat. Soil Erosion Research Laboratory, West Lafayette, IN.

Beuselinck, L., P.B. Hairsine, G.C. Sander, and G. Govers. 2002. Evaluating a multi-class net deposition equation in overland flow conditions. Water Resour. Res. 38:DOI:10.1029/2001WR000250.

Cheng, N.-S. 1997. Simplified settling velocity formula for sediment particle. J. Hydraul. Eng. ASCE 123:149-152.

Ciesiolka, C.A.A., K.J. Coughlan, C.W. Rose, M.C. Escalante, G.M. Hasim, E.P. Paningbatin, Jr., and S. Sombatpanit. 1995. Methodology for a multi-country study of soil erosion management. Soil Technol. 8:179-192.

Croley, T.E. 1982. II. Unsteady overland flow sedimentation. J. Hydrol. (Amsterdam) 56:325-346.

de Roo, A.P.J., C.G. Wesseling, and C.J. Ritsema. 1996. LISEM: A single-event physically based hydrological and soil erosion model for drainage basins. I. Theory, input and output. Hydrol. Processes 10:1107-1117.

Flanagan, D.C., and M.A. Nearing. 2000. Sediment particle sorting on hillslope profiles in the WEPP model. Trans. ASAE 43:573-583.

Foster, G.R. 1982. Modeling the erosion process. p. 297-360. In C. T. Haan (ed.) Hydrologic modeling of small watershed. ASAE Monogr. No. 5 .

Foster, G.R., D.C. Flanagan, M.A. Nearing, L.J. Lane, L.M. Risse, and S.C. Finkner. 1995. Ch. 11 Hillslope erosion component. p. 11.1-11.13. In D.C. Flanagan and M.A. Nearing (ed.) USDA-Water Erosion Prediction Project: Hillslope Profile and Watershed Model Documentation. NSERL Rep. No. 10. USDA-ARS Nat. Soil Erosion Research Laboratory, West Lafayette, IN.

Foster, G.R., and L.D. Meyer. 1972. A closed-form soil erosion equation for upland areas. p. 12.1-12.19. In H.W. Shen (ed.) Sedimentation. Colorado State University, Fort Collins, CO.

Hairsine, P.B., and C.W. Rose. 1991. Rainfall detachment and deposition: Sediment transport in the absence of flow-driven processes. Soil Sci. Soc. Am. J. 55:320-324.

Hairsine, P.B., and C.W. Rose. 1992. Modelling water erosion due to overland flow using physical principles: I. Uniform flow. Water Resour. Res. 28:237-244.

Hairsine, P.B., G.C. Sander, and L. Beuselinck. 2002. Sediment transport through an area of net deposition. Water Resour. Res. 38: DOI:10.1029/2001WR000265.

Hairsine, P.B., G.C. Sander, C.W. Rose, J.-Y. Parlange, W.L. Hogarth, I. Lisle, and H. Rouhipour. 1999. Unsteady soil erosion due to rainfall impact: A model of sediment sorting on the hillslope. J. Hydrol. (Amsterdam) 199:115-128.

Heilig, G.C., D. DeBruyn, M.T. Walter, C.W. Rose, J.-Y. Parlange, T.S. Steenhuis, G.C. Sander, P.B. Hairsine, W.L. Hogarth, and L.P Walker. 2001. Testing a mechanistic soil erosion model with a simple experiment. J. Hydrol. (Amsterdam) 244:9-16.

Huang, C., L.K. Wells, and L.D. Norton. 1999. Sediment transport capacity and erosion processes: Model concepts and reality. Earth Surface Processes Landforms 24:503-516.

Laflen, J.M., W.J. Elliot, D.C. Flanagan, C.R. Meyer, and M.A. Nearing. 1997. WEPP-Predicting water erosion using a process-based model. J. Soil Water Conserv. 52:96-102.

Misra, R.K., and C.W. Rose. 1995. An examination of the relationship between erodibility parameters and soil strength. Aust. J. Soil Res. 33:715-732.

Misra, R.K., and C.W. Rose. 1996. Application and sensitivity analysis of process-based erosion model GUEST. Eur. J. Soil Sci. 47: 593-604.

Morgan, R.P.C., J.N. Quenton, R.E. Smith, G. Govers, J.W.A. Poesen, K. Auerswald, G. Chisci, D. Torri, and M.E. Styczen. 1998. The European soil erosion model (EUROSEM): A dynamic approach for predicting sediment transport from fields and small catchments. Earth Surface Processes Landforms 23:527-544.

Nearing, M.A., G.R. Foster, L.J. Lane, and S.C. Finkner. 1989. A process based erosion model for USDA water erosion prediction project technology. Trans ASAE 32:1587-1593.

Proffitt, A.P.B., P.B. Hairsine, and C.W. Rose. 1991. Rainfall detachment and deposition: Experiments with low slopes and significant water depths. Soil Sci. Soc. Am. J. 55:325-332.

Proffitt, A.P.B., P.B. Hairsine, and C.W. Rose. 1993. Modelling soil erosion by overland flow: Application over a range of hydraulic conditions. Trans ASAE 36:1743-1753.

Rose, C.W. 1985. Development in soil erosion and deposition models. Adv. Soil Sci. 2:2-63.

Rose, C.W. 1993. Erosion and sedimentation. p. 301-343. In M. Bonnell et al. (ed.) Hydrology and water management in the humid tropics-Hydrological research issues and strategies for water management. Cambridge University Press, Cambridge.

Rose, C.W. 1998. Modeling erosion by water and wind. p. 57-88. In R. Lal, W.H. Blum, C. Valentine, B.A. Stewart (ed.) Methods for assessment of soil degradation. CRC Press, Boca Raton, FL.

Rose, C.W., K.J. Coughlan, C.A.A. Ciesiolka, and B. Fentie. 1997. Program GUEST (Griffith University Erosion System Template). p. 34-58. In K.J. Coughlan and C.W. Rose (ed.) A new soil conservation methodology and application to cropping systems in tropical steeplands. ACIAR Tech. Report, No. 40, Canberra. Australian Centre for International Agriculutural Research, Canberra, Austrailia.

Rose, C.W., J.R. Williams, G.C. Sander, and D.A. Barry. 1983. A mathematical model of soil erosion and deposition processes: I. Theory for a plane land element. Soil Sci. Soc. Am. J. 47:991-995.

Sander, G.C., P.B. Hairsine, C.W. Rose, D. Cassidy, J.-Y. Parlange, W.L. Hogarth, and I. Lisle. 1996. Unsteady soil erosion model, analytical solution and comparison with experimental results. J. Hydrol. (Amsterdam) 178:351-367.

Sander, G.C., P.B. Hairsine, L. Beuselinck, and G. Govers. 2002 Steady state sediment transport through an area of net depositions. Water Resour. Res. 38:DOI:10.1029/2001WR000323.

Yu, B., and C.W. Rose. 1999. Application of a physically based soil erosion model in the absence of data on runoff rates: I. Theory and methodology. Aust. J. Soil Res. 37:1-11.

Yu, B., A. Sajjapongse, D. Yin, Z. Eusof, C. Anecksamphant, C.W. Rose, and U. Cakurs. 1999. Application of a physically based soil erosion model in the absence of data on runoff rates: II. Four case studies from China, Malaysia and Thailand. Aust. J. Soil Res. 37: $13-31$. 